\title{
Activated Lymphocytes Measurement
}

National Cancer Institute

\section{Source}

National Cancer Institute. Activated Lymphocytes Measurement. NCI Thesaurus. Code C119289.

The determination of the amount of activated lymphocytes in a biological specimen. 